\title{
OPINION
}

\section{Racial profiling for induction of labour: improving safety or perpetuating racism?}

\section{Christine Douglass, Amali Lokugamage}

The disproportionate mortality and morbidity in mothers and babies from black, Asian, and ethnic minority backgrounds as compared with white mothers and babies is clearly evidenced. ${ }^{1-3}$ Efforts to tackle the issue have been made at a national level. For example, the Royal College of Obstetricians and Gynaecologists (RCOG) held a public engagement event and developed partnerships with maternity user groups. ${ }^{45}$ However, in an attempt to lessen this disproportionate morbidity and mortality, the National Institute for Health and Care Excellence (NICE) has, within its new draft guidelines for induction of labour, a suggestion of racial profiling. It recommends that women from ethnic minority backgrounds should consider having their pregnancy induced at 39 weeks, even if the pregnancy has no complications. ${ }^{6}$ The recommendations have led to a significant backlash from advocacy groups and doctors. $^{\text {-9 }}$

Historic, systemic biases in medicine have arisen from biological determinism. A paper on race based medicine by Cerdeña et al pointed to inherent biases that are pernicious and ongoing within clinical medicine. ${ }^{10}$ Proponents of critical race theory argue that race is a social and political construct where "bodies inherit not merely genes, but power relationships, legacies of discrimination, the ideological effects of past social policy, and generational systems of belief." 11 Nevertheless, intersectional oppressions can lead to the epigenetic phenomena of weathering, where hardships can produce disease pathology. ${ }^{12}$ Thus, making recommendations based on race alone must be critically evaluated and never undertaken in isolation.

We are deeply concerned that if these recommendations are taken forward uncritically, they could further embed institutional racism in maternity care, strengthen racial biases and stereotypes, legitimise skin tone as clinically meaningful, pathologise healthy pregnancies in women from ethnic minority backgrounds, and undermine choice for black and brown women.

We want to draw attention to the concept of Cultural Safety, in which structural reflexivity is more important than reflectivity. ${ }^{13}$ "Reflectivity" involves analysing what has happened. However, "reflexivity" involves self or institutional assessment, evaluation of power imbalances, and reaction to the circumstances as they are happening. Its purpose is to look inwardly and outwardly in a social context. This would lead to critically appraising the evidence base for structural or institutional racism; acknowledging race as a social construct and racism as a determinant of health; recognition of the lived experiences of women from ethnic minorities and birthing people within healthcare systems; and co-production as essential in generating guidelines.

In the NICE evidence review for the draft guidelines, the lack of direct evidence for women from ethnic minorities is noted by NICE. Of the studies referenced, most did not record race or were unable to, or failed to report on ethnic variation owing to low numbers of minority ethnic women. ${ }^{14}$ This "absence" of evidence could be construed as a form of structural racism.

Attention has been drawn to older studies from routine data sets that suggest different gestation lengths for women from ethnic minorities in comparison with white women. ${ }^{15^{-17}}$ In critically appraising this further, these routine data are of a lower quality and not from controlled trials. Studies from older routine health data can fall prey to bias, and indeed mask or conceal structural discrimination and racism, and should be used only as a signal for launching better studies. Indeed, an examination of a data set of birth outcomes for African and Caribbean babies in England and Wales makes a case against over homogenisation of women from ethnic minorities. ${ }^{18}$

In a statement from the RCOG about NICE's draft guidance, the college implies that induction has no downsides, but it doesn't seem to have taken into account the recent long term adverse outcomes data for inductions of labour in uncomplicated pregnancies from Australia, or the increasing evidence that the risk of stillbirth is reduced by amplifying continuity of midwifery care models. ${ }^{19-22}$ Achieving high quality national guidance also requires an examination of the impact of social, cultural, and political systems on health, wellbeing, safety, access to care, quality of care, and autonomy. Structural racism is pervasive across British society. Racism is a known determinant of health, occurring at systemic and individual levels. Its role in perpetuating the extreme disparities witnessed in maternity care needs to be addressed through "race conscious medicine" as described by Cerdeña et al. ${ }^{10}$

Experiential data can enhance critical analysis by positively challenging biases and reductive stereotyping and exposing racism that quantitative data may conceal. Widespread qualitative data show that women in all ethnic minority groups have poorer experiences of care across antenatal, intrapartum, and postnatal stages than white women. ${ }^{23}$ Bringing together experiential knowledge and priorities with 
clinical knowledge and priorities in co-production processes would increase not only the quality of guidance but increase confidence in it, and help achieve individualised care for all women and reduce coercion. While NICE has been emphatic that guidelines should not be tramlines, efforts to address the lack of birthing women's autonomy in induction of labour require significantly more attention. ${ }^{24} 25$

The conversations around the NICE draft guidelines provide strong justification for structural reflexivity, "race conscious" medicine, and co-production. ${ }^{1013}$ The opportunities for real change should not be overlooked. If indeed future higher quality studies reveal different gestation lengths for women and birthing people from ethnic minorities, there should be no delay in presenting these data to stakeholders.

Competing interests: CD is chair of the BMA Patient Liaison Group. AUL is on the board of directors o the International MotherBaby Childbirth organisation and is also a member of the Patient and Public Voice Partners for NHS England, in both cases deriving no financial remuneration. AUL is a company director of a small publishing company called Docamali Ltd.

We are grateful to Logan Van Lessen for reviewing the manuscript and alerting us to the importance of continuity of midwifery care models.
17 Balchin I, Whittaker IC, Patel RR, Lamont RF, Steer PJ. Racial variation in the association between gestational age and perinatal mortality: prospective study. BMJ 2007;334:833. doi: 10.1136/bmj.39132.482025.80. pmid: 17337455

18 Datta-Nemdharry P, Dattani N, Macfarlane AJ. Birth outcomes for African and Caribbean babies in England and Wales: retrospective analysis of routinely collected data. BMJ Open 2012;2:e001088. doi: 10.1136/bmjopen-2012-001088. pmid: 22619268

19 RCOG. RCOG responds to NICE draft guidelines on induced labour. July 13. 2021.https://www.rcog.org.uk/en/news/rcog-responds-to-nice-draft-guidelines-on-induced-labour/

20 Dahlen HG, Thornton C, Downe S, etal. Intrapartum interventions and outcomes for women and children following induction of labour at term in uncomplicated pregnancies: a 16-year population-based linked data study. BMJ Open 2021;11:e047040. doi: 10.1136/bmjopen-2020-047040. pmid: 34059509

21 NHS. Targeted and enhanced midwifery-led continuity of carer. https://www.england.nhs.uk/ltphimenu/maternity/targeted-and-enhanced-midwifery-led-continuity-of-carer/

22 Sandall J. Measuring Continuity of Carer: A monitoring and evaluation framework. 2018. https://www.rcm.org.uk/media/2465/measuring-continuity-of-carer-a-monitoring-andevaluation-framework.pdf

23 Henderson J, Gao H, Redshaw M. Experiencing maternity care: the care received and perceptions of women from different ethnic groups. BMC Pregnancy Childbirth 2013;13:196. doi: 10.1186/1471-2393-13-196. pmid: 24148317

24 David Haslam. Getting the guidance right. NICE. 2016.https://www.nice.org.uk/news/feature/davidhaslam-getting-the-guidance-right

25 Skyrme L. Induction of labour for post-term pregnancy. Br J Midwifery 2014;22. doi: 10.12968/bjom.2014.22.6.400.
1 Knight M, Bunch K, Tuffnell D, et al. MBRRACE-UK. Saving lives, improving mothers' care - lessons learned to inform maternity care from the UK and Ireland Confidential Enquiries into Maternal Deaths and Morbidity 2015-17. Oxford: National Perinatal Epidemiology Unit, University of Oxford: 2019. https://www.npeu.ox.ac.uk/assets/downloads/mbrrace-uk/reports/MBRRACE-UK Maternal Report 2019

2 Knight M, Bunch K, Tuffnell D, et al. MBRRACE-UK. Saving Lives, Improving Mothers' Care Lessons Learned to Inform Maternity Care from the UK and Ireland Confidential Enquiries into Maternal Deaths and Morbidity 2014-16. Oxford: National Perinatal Epidemiology Unit, University of Oxford: 2018. https://www.npeu.ox.ac.uk/assets/downloads/mbrrace-uk/reports/MBRRACEUK Maternal Report

3 Draper E, Gallimore I, Smith L, etal. MBRRACE-UK Perinatal Mortality Surveillance Report, UK Perinatal Deaths for Births from January to December 2018. The Infant Mortality and Morbidity Studies, Department of Health Sciences, University of Leicester, 2020,

https://www.npeu.ox.ac.uk/assets/downloads/mbrrace-uk/reports/perinatal-surveillance-report2018/MBRRACE-UK_Perinatal_Surveillance_Report_2018_-_final_v3.pdf.

4 RCOG. International Women's Day 2020: We need to talk about race. 2020.https://www.rcog.org.uk/en/news/campaigns-and-opinions/international-womens-day/international-womens-day-2020/

5 RCOG. RCOG and Five X More launch joint campaign to tackle racial disparities in maternity care 2020.https://www.rcog.org.uk/en/news/rcog-and-five-x-more-launch-joint-campaign-to-tackleracial-disparities-in-maternity-care/

6 NATIONAL INSTITUTE FOR HEALTH AND CARE EXCELLENCE. Guideline. Inducing labour. Draft for consultation. May 2021. https://www.nice.org.uk/guidance/GID-NG10082/documents/draftguideline-2

7 OBS. The \#notsonice campaign. Published Online First: 2020.https://the-obs.co.uk/notsonice/

8 Birthrights. Induction proposals ignore black and brown women's experience of maternity services. 2020.https://www.birthrights.org.uk/2021/07/05/induction-proposals-ignore-black-and-brownwomens-experience-of-maternity-services-says-birthrights/

9 Mahase E. Doctors question NICE recommendation to induce labour at 39 weeks in ethnic minority women. BMJ2021;374:n1711. doi: 10.1136/bmj.n1711. pmid: 34230033

10 Cerdeña JP, Plaisime MV, Tsai J. From race-based to race-conscious medicine: how anti-racist uprisings call us to act. Lancet 2020;396:1125-8. doi: 10.1016/S0140-6736(20)32076-6. pmid: 33038972

11 Bridges KM, Keel T, Obasogie OK. Introduction: Critical race theory and the health sciences. Am J Law Med 2017:43:179-82. doi: 10.1177/0098858817723657. pmid: 29254469

12 Simons RL, Lei MK, Beach SR, etal. Economic hardship and biological weathering: The epigenetics of aging in a U.S. sample of black women. Soc Sci Med 2016;150:192-200. doi: 10.1016/.j.socscimed.2015.12.001. pmid: 26765221

13 Lokugamage AU, Rix E, Fleming T, et al. Translating Cultural Safety to the UK. J Med Ethics 2021 doi: 10.1136/medethics-2020-107017

14 NICE. Inducing labour [C] Induction of labour for prevention of prolonged pregnancy. NICE guideline number CG70 (update) Evidence review underpinning recommendations. 2021. https://www.nice.org.uk/guidance/gid-ng10082/documents/evidence-review-3

15 Picart S, Frimpong T. Response to the recent draft NICE guideline on induction of labour (part 1) with my friend and fellow obstetrician Tejumola Frimpong. Faceb. Post. 2021;July.https://www.facebook.com/stacey.ferguson.3910/videos/361521055548639

16 Balchin I, Whittaker JC, Lamont RF, Steer PJ. Timing of planned cesarean delivery by racial group. Obstet Gynecol 2008:111:659-66. doi: 10.1097/AOG.0b013e318163cd55. pmid: 18310369 